ISSN 1112-9867

\title{
THE SURVEY OF PEDESTRAINIZATION FEASIBILITY IN URBAN SPACES AND ITS RELATIONSHIP WITH THE CITIZENS' VIVACITY CASE STUDY: THE CITY OF BIRJAND'S HAKIM NAZARI STREET
}

\author{
M. Alimardani ${ }^{1}$; M. Aftabi ${ }^{2}$; A. Dehghani ${ }^{3}$ \\ ${ }^{1}$ Shahid Raja' ee teacher training university, assistant professor and dean of the city design \\ faculty. \\ ${ }^{2}$ Shahid Raja'ee teacher training university, BA student, city design department \\ ${ }^{3}$ Noor-e-Tooba non-for-profit virtual higher education institute, BA student, city planning \\ department
}

Published online: 16 July 2016

\begin{abstract}
The current article aims at the survey of the feasibility of transforming Hakim Nazari Street to a walk way along with the social vivacity and it is seeking to find an answer to the question proposed in the current research project which states that "whether Hakim Nazari St. has the potential to be changed into a side walk causing a higher deal of social spirit?" and it is also in search of proving the study hypothesis implying that "it seems that Hakiim Nazari St. is capable of being transformed into a side walk with social vivacity through taking all its potentials and capabilities into practical use". Firstly, we deal with the survey of the specialized contexts and try to extract the scales and standards of building sidewalks feasibilities and likelihoods and its relation with the citizens' vivacity through making use of a descriptive-analytical method and in the form of documentary-library researches and after that the extracted items have been investigated and evaluated through field studies and questionnaire and interviewing with the space users.
\end{abstract}

Author Correspondence,e-mail: ma_alimardani@yahoo.com

doi: http://dx.doi.org/10.4314/jfas.v8i2s.104 
The questionnaire has been designed structurally in two parts of pedestrian-oriented indicators and indices and the citizens' vivacity and joyfulness and the questionnaires have been distributed in 6 days (all week days) and various hours (morning, noon, night) to 320 people from both male and female genders with an age range of 15 to 65 years and from different social classes and groups (residents, businessman and woman, space users) based on a systematic randomized method on the street and finally the questionnaires have been collected and the data extracted thence have been analyzed. The current study indicates that Hakim Nazari Street based on the sidewalk indices and because of scoring 2.23 from the total of 3 points has the potential to be changed into a sidewalk and the study hyyupothesis has been confirmed following the researches and investigations carried out.

Keywords: building sidewalks, vivacity, urban spaces, Hakim Nazari Street

\section{INTRODUCTION:}

Given a comprehensive definition of the city it can be stated that the city is the grounding for the presentation and display of the gatherings culture and civilization, life fundamental contexture manifestation (social, economical, religious and political) and it is an organized habitat which forms the arena for the human activities (Izadi, 2010). The most important pillar in the cities which forms the area for the human beings activities is the urban spaces. Urban spaces are not the empty spaces between the buildings rather it is a concept which encompasses the physical environment, the individuals, events and the interrelationships between them (Madanipoor, 2008). The urban spaces play a significant role in shaping the mental image and identification and it has also been shown to have a particular stance (Rafi'eean, 2010). Nowadays, in developing countries paying attention to the people's presence in urban spaces plays a key role in designing and planning the cities. And the vital key in achieving a successful, vivacious, safe, sustainable and healthy city is in focusing on the people's roe and their needs. It is more similar to the attention paid to the human aspect of development, having access to spaces with high environmental qualities and according to the people's prestige and positions and enhancement of the quality in public areas in the urban designing and planning. It is based on such an idea that the public spaces and the development of the social activities in such areas are under so much pronounced concentration (Izadi, 2011). Favorable and optimum areas and collective spaces in accordance to the culture, social features and needs proportionate to the environmental 
conditions can be regarded as an undeniable value in the optimality of the today's urban life spaces (Ghaffari and Soheilipoor, 2010). In the today's look adopted by the urban policy-makers and planners a good city is the place where the people interact socially and culturally, a good city is the city where people can listen and talk, watch and experience, a good city is a vivacious diverse place safe for movement and dynamicity and a good city is a city where the others can stop and walk (Izadi, 2011). During the last three decades that the urban problems have become more acute, also due to the bioenvironmental pollutions, difficulties in the traffic, road insecurities, the cities' historical centers crises and the decline in the urban spaces qualities, convenience and purchase problems and service availabilities, elevation of the psychological pressures and so many others have brought about an extensive movement against motorized vehicles and for the pedestrians activities worldwide which has been followed with the expansion of the sidewalk spaces in the advanced countries. Following the movement the sidewalks came under serious focus of the city builders and planners (Fallah Manshadi et al, 2012). Footpaths or the sidewalks are the passages with the highest limit social role on which the pedestrians and footers have the absolute dominance and such passages usually take the form of alleys, bazaars, small malls, venues inside the square spaces, parks or the spaces inside a building block which can be served for spending citizens' leisure time (Mortazavi, 2011).

History: pedestriansation can be defined in this way that before industrial revolution the city forming and shaping elements sizes and fixations were based on the human scale and the movement pattern was according to the footer mobility; that means that the pedestrian determined the sizes and the distances (Gharib, 2004), after the outset of the industrial revolution and following the modernist thought dominance and especially by the proposition of the theory of "appropriate city with personal cars" the role and importance of the footpaths lost their color and gradually the pedestrians lost their stance and superiority in the urban spaces. On the other hand, the zoning policies and the segregation of the performances and urban uses during the modern city building period caused the cities to be deprived of their dynamicity and vitality the result of which was the appearance of the cities with congruent regional segregation, isolation of the social classes from one another and omission of the diverse activities from the cities. Such an issue did not have any other results than the elimination of vivacity and vitality from the cities' 
central parts (Abbaszadegan, 2004). Such a procedure has brought about numerous problems and issues in the great many of the world cities such as the wastage of the facilities and natural resources, decline of the city centers activities, especially the traditional centers, the increase in the number of city accidents, seclusive life styles and generally diseases stemming from machine life (Muhamadzadeh, 1995). Following the failure of the modern city building processes and the human development and environment discussions and topic finding more articulated importance a lot of criticisms were directed towards modern city building activities by the city-related subject matters theoreticians. The criticisms sharp edge was substantially pointed towards the textural quality, the unfavorable and adverse spaces resulting from the city building system. Therefore, in struggling for finding appropriate solutions for proposing a city plan favored by the citizens in confrontation with the unorganized status of the modern city building many novel attitudes and perspectives were posited in the city building arena. In the meantime, the authors writing texts about city and city-related issues including Louise Mumford, Bernard Rudofsky, Jin Jacobs and William $\mathrm{H}$. White voted for the potential probability of returning sidewalks and pavements to the cities which had been destroyed and vanished due to the vehicles traffic (Frain, 2004).

Urban planners and designers remind this aspect of the pedestrians as a basic part of the city life and it is not envisaged as an interferer to the main part, to wit the automobiles (Pakzad, 2005). Walking and sidewalk footing have so much expanded in the cities that the contemporary city building aspects consider it as their main principles superiority and the documents of the city guidance in the majority of the cities have enlisted this topic on top of their objectives list. Consequently, through adopting to look at the issue from this perspective many sidewalks were built inside the cities and these spaces were taken into consideration as the ones which provide for the necessary, selective and social activities and the urban management took steps in line with the persistent quality improvement of such spaces. Making efforts for enhancing the quality of the sidewalks has recently turned into so important an idea that these spaces are utilized for tourist attraction.

Paying serious attention to the organization of the pedestrians' movement and the sidewalks dates back to the late 1940s. In European cities such an idea was proposed and implemented with the objective of taking the historical areas out from the automobiles' domination and preserving the old textures and socially revitalizing the city centers (Habibi, 2001). Taking this issue into 
consideration found a more pronounced and more definite form after the World War II at the time for rebuilding the European cities. In American cities, at the early 1960s the tendencies and propensities for returning to the city centers strengthened and there were formed pavement and sidewalk streets called malls which were more parallel to the idea of expanding and enhancing business transactions and intentions and in the meantime their goal was to create favorable environments for purchase and recreation in the cities. Later on following to building pedestrianspecific pass ways these not only play an undeniable role in renewing the city centers but they also provide the citizens with spaces for social interactions in which they can focus their senses on scene selection, visual enjoyment and/or untroubled walking in a calm and safe environment without being constantly obsessed with the danger of having a car accident (Ghorbani and Jam Kasra, 2010). The primitive prototypes of the sidewalks were built in the cities of Osen and Kassel in Germany, Rotterdam in Holland and the Country in England. The first of these pedestrian walk ways in the US was built in Kalamazoo 5 in 1959 and the second one was built in Miami Beach 6 in 1960. The common feature for all of these was to give priority to the presence of the pedestrians pursuing the objective of civil life revival (Shaghaghi, 2007).

Importance and necessity: the current study has been undertaken with the objective of defining sidewalks as the most significant facility for watching the localities, performing activities and feeling excited and astonished and sensing the life mobility and discovering the latent attractions and values in the environment. Walking life in the city is the main and primary element of the society formation and it is the spirit of the city and the feeling of being belonged to a locality and feeling that it is part of your belongings and holdings which can lead to citizens' tranquility and psychological balance depends on the urban environment experiences (Ashoori, 2010). And the sidewalks as part of the urban spaces bring about an area for the social and political incidents to take place, create memories and provide the collective feelings with an opportunity to be expressed (Mortazavi, 2011). Moreover, the walk way areas in spite of many of the other spaces utilized for spending leisure times can serve diverse and variegated functions that can attract the people from any age and gender (kashani Joo, 2006).

Along with these issues stated above, the current research aims at the feasibility survey of transforming Hakim Nazari Street into a walkway considering the social vivacity. And the main question sought for in the present study is that: 
- Whether Hakim Nazari Street possesses the potential to be transformed into a walkway with social vivacity?

And the main study hypothesis has also been put forth in the following form:

- It seems that Hakim Nazari Street possesses the potential to be turned into a sidewalk with social vivacity through possessing its unique elements and competencies.

In the present study firstly we deal with the survey of the specialized contexts regarding the standards and norms of pedestriansation and its relation with a vivacity component and then it has been tried to investigate the extracted ideas and notions through field studies and interviews with the users of Hakim Nazari Street space.

\section{Study theoretical principles:}

The present study incorporates two main topics taken into consideration by the author as needed which include a review of the pedestrian-orientation and vivacity.

\section{Pedestriansation and the sidewalk concept:}

Sidewalks and walking malls are streets in which the vehicles' interference has brought to a minimum or eliminated and they are passages with the highest social roles (Pakzad, 2005). Sidewalks are means of collective movement and they are especially linked to urban economy, environment quality and social health. The walking or pedestrians' malls or purchase centers in the modern era are more similar to the medieval plazas (Frain, 2004).

Pedestriansation is the most powerful and the most effective movement in redesigning the streets which has brought about subtle changes in the public urban environments in the majority of the cities and the European and American planners have fetched considerable accomplishments in reviving the city centers through making use of such plans and via limiting the traffic to the main streets. In 1970s to 1980 s such a movement led to the construction of 150 malls in small and large cities in the US (Berambilla and Gionni, 1977). Pedestriansation is taken to mean a process during which the streets spatial aspects are retaken from the automobiles and the other vehicles and consequently appropriate measures are undertaken such as stone paving, adding furniture and the other details (Hass, 1990). In Manheim's idea (1975) the paved street can be defined as "the street which is only used by the pedestrians, and also they can be accessed by the cargo transporting vehicles which is made possible only during certain hours, and the public transportation vehicles and cargo trucks substantially have access to the dorsal streets and alleys". Pedestriansation also implies repelling the traffic to the places outside the city centers 
following which procedure appropriate operations are carried out such as street paving and adding furniture. Such operations can be practiced for one single street or the entire network of the streets (Hass, 1990). Pedestriansation is one of the traffic limitation policies which is conducted with the purpose of reducing the harmful effects of harmful bioenvironmental effects as a result of automobile-orientation approaches, increasing the pedestrians' safety, reclaiming the urban spaces for the footer uses free of motorized vehicles traffic only and radical improving the urban environment as a dwelling place (Habibi, 2001). Barden (2001) has determined 6 essential needs for the people who refer to the retailing shops, service centers, streets, neighborhoods or the cities. These 6 fundamental needs are safety, efficiency, comfort, receptiveness, welfare, inter-community or inter-society interactions and relations. All such needs can be traced into the pedestrianized streets (Shaghaghi, 2007).

\section{The pedestriansation objectives:}

Some of the objectives for making auto-free precincts have been stated by Lockwood, they can be presented below:

- Enhancing the environment and street attraction

- Increasing the value of the estates

- Reduction in the need for authorizing and regulating the traffic

- Reducing the vehicles side effects and negative impacts on the environment

- Creating streets with beautiful landscapes

- Reducing the motorized vehicles motion speed in the streets

- Increasing the safety for the pedestrians or cyclers

\section{Factors effective on the walking and cycling attractiveness:}

- The city size and density: highly dense and smaller regions are more auspicious for walking and cycling since the destinations are shorter and therefore are more within reach

- Distance and time: the traveling time particularly in constructed precincts influence the transportation state between the destination and the source.

- Environmental status: the weather and the climate and the topographical features are among the factors which can hinder the people's use of the non-motorized states for shorter trips within the context of the urban transportation network. When the weather is unfavorable despite the short distance the people may prefer to travel by vehicles. 
- Non-motorized infrastructures: if there are were no cycling, sidewalk and passage ways people's daily traffic by these states of transportation and movement would be prevented. Moreover, other barriers and prohibiting factors such as high tiles and curbs, inappropriate pavements, the existence of road blockers and the danger of the cars' doors hitting the cyclists and the others cause difficulties in making use of such states. The other factors which prevent the people from using bicycles are the lack or the deficiency in the existence of bicycle parking lots.

- Personal safety: high speeds and the wide and congested traffic volume, the high number of the accidents with the footers and the road deaths, committing offences and particularly fear of crimes are among the problems which prohibit the people from walking and cycling.

- Troublers: carrying food stuff and the other heavy items, taking children to and from schools or carrying the other passengers, the need for the vehicles at work are among the barriers to the jogging and walking and cycling.

- Culture, treatment style and habits: unfortunately, sometimes some communities including our country consider cycling and walking as being of low prestige and class and they refrain from practicing these activities accordingly.

- Public transportation and the linkage between the other transportation states: there is no doubt that the people are looking for transportation with the maximum comfort, the least triptime to the destination and highly reliable services from their sources to their destinations and vice versa.

- Linking and bonding the other transportation forms along the sidewalks: it is considered as another factor which is effective on the walking and jogging attractions and also the pedestrianisation plans accomplishment.

- Comfort: the pedestrian comfort, positive affective reaction to the external environment, walking environment and the situation which includes physiological, physical, social and psychological reactions. Factors contributing to the pedestrian comfort are many, but the most important of them can be pointed out as heat comfort, visual comfort, auditory comfort, tactile comfort, olfactory comfort, air pollution and allergies, the ease with which they move and the feeling of safety and security, appropriate social contacts and interactions spaces, proper furniture, WCs, vegetative cover, or the suitable topography and appropriate weather. People only walk when there is a convenient condition and a pleasant environment for them 
and it is in this way that the people turn to open social spaces (Mohammadyan Mosammam, 2012).

- Efficient navigation and routing systems: it includes shortening the travelling distance length, improving the continuity of the road block, reducing the trip length, the reduction in the useless and wasting application of the transportation services (bus, underground), pedestrian's reduction of confusion and wandering, awareness of the distances and the lengths which causes the use of and practicing the walking state, changing the environment quality, increasing the pedestrian self-confidence, increasing the pedestrian satisfaction and the easy and ready positioning of the pedestrians.

\section{The policies for enhancing walking and cycling:}

1. Clarifying the pedestrians and cyclists legal rights (there is observed a lack of comprehensive programs and plans in civil rights and city-building regulations; traffic regulations, criteria related to the sidewalks and pedestrians' rights and duties regarding the pedestrians and pedestrianisation) (Mo’eeni, 2012).

2. Expanding the walking and jogging facilities (can include cycling routes which are either separate from the pedestrians' routes or they are blended, the increase and improvement of the sidewalks, pedestrians bridges, benches for resting and sitting, fountains, water view, appropriate zebra lining, accurate navigation and routing, safe and sound shelves for parking the bicycles).

3. Integrating the non-motorized states with public transportation (since the pedestrian and cyclist trips is not possible to every corner of the city, enhancing public transportation systems and integrating the footers and the cyclers trips with the public transportation vehicles along the path seems to be a necessity).

4. Expansion and intensification of the political exercises and social participation (to create changes in the public policies and encouraging safer walking and cycling are among the necessary undertakings and procedures).

5. Economical tools: (these can be useful for the implementation and practicing of the policies regarding the reduction of vehicles uses and also increasing the cycling and footing states shares) and they include (Mohammadian Mosammam, 2012):

- Road congestion pricing: in such a manner that the drivers are to pay fees for their driving especially in peak traffic hours. But if the money earned from the pricing is used for the 
construction of more motorized-vehicles roads; and if the drivers make use of the tributary paths and the neighborhoods for escaping and ducking away the road tolls, then, unfortunately the congestion pricing does not lead to a decrease in vehicles dependency)- fuel tax, vehicles tax, taxes on air pollution emitting, parking lots pricing.

6. Pedestrian streets and precincts standards: (these standards deal with ideas such as speed determination and the sidewalks width, streets, alleys, residential areas and neighborhoods, pedestrians' crossing zebra lines, curbs height, aerial cabling and public utilities (water and electricity), type of lighting system and so many other issues of the like).

The role of the pedestrian roads: development of the walkways and human-oriented urbanization can be elucidated from various and numerous technical aspects but what is here intended by the author are the roles which tie the people to the locations and revive memory and vivacity. The most substantial of these roles are: (Ashouri, 2010), (Kashani Joo, 2011):

- Perceptional role: the most significant function expected from a road is the use of experiencing movement for perceiving concomitantly the texture and the city memory. The sidewalks cause the citizens' mental image to be enhanced through attracting the attentions towards the historical and social locations.

- Social role: walking on foot causes the citizens to more frequently and informally meet each other and this incident contributes to a more pronounced and articulated social participation and communication and therefore it can be used as a tool for reducing the social crimes and offences.

- Economical roles: one of the main targets of the sidewalk footing is its application as a development driving force which is effective on the environment whether social or textural.

- Recreational role: city jaunting is one form of spending leisure times and the sidewalks can play the most outstanding role in satisfying such needs.

- Bioenvironmental roles: pedestrian-oriented plans are considered as one of the most important tools and means of sustainable urban development. Nowadays, supporting and protecting the environment-friendly and environmentally consistent traffics and like pedestrianization one can take positive steps regarding creating more car-free precincts in the cities. This is a procedure which can result in creating value and income and reducing the air pollution and saving energy. 
The importance of organizing sidewalks in the urban spaces: the main objectives sought for by planning for the organization of the sidewalks are: safety, security, comfort, unity, convenience, system integration and attractiveness (Pakzad, 2005; Kashanijoo, 2011; Kashanijoo, 2006; Thaghafi Asl, 2008; Southworth, 2005; Frain, 2004).

- Sidewalk safety: it includes the reduction or the elimination of the conflicts between the vehicles and the pedestrians as a result of segregating the space.

- Sidewalk security: buildings and streets configuration should be conducted in a manner that it makes it possible for the pedestrians to be observable and visible by the others.

- Pedestrians' comfort: it includes topics such as their easy dislocation and movement of the postal boxes, telephone kiosks, newspaper booths, garbage bins and flower pots, traffic light posts footers, fire extinction taps and pumps and the firefighters' siren packages from the pedestrian sidewalks, installing touchable signs for the blind peoples in the buildings and urban localities, securing shelters in bus stops, covered porches, benches and providing for the public access facilities.

- Unity: there is no need to take so much fuss over the issue of the systems unity and integrity, that is to say that the sidewalks modifications should be made direct, available and along the pedestrians' normal paths.

- System integrity: if we are to actualize the space perfect usefulness the visual and functional integrity and coherence are necessary elements for designing.

- Attractiveness: creating landscapes, the color and the texture of the pavements, street furniture, fountains and plazas should be well-designed in order for the visual diversity of the city visage to be enhanced. The existing opportunities and chances for offering wonderful elements by taking advantage of the outlooks and wide and broad vistas should not be overlooked.

Sidewalks evaluation scales: more than anything else one has to be careful that in placement and establishment and designing the sidewalks it is necessary to take various aspects into consideration and sociologists and social thinkers and theoreticians can also play a significant role in the emergence of the pedestrian-orientation approaches besides the city builders and environment designers. Due to the same reason, the sidewalk planning and designing does not contain only textural and traffic aspects, rather it is accompanied with broad and extensive social and cultural goals (Ghorbani and Jam Kasra, 2010) and here four aspects 
such as social-economical, spatial, accessibility and traffic dimensions have been taken into consideration for introducing and offering the indices and scales:

1. Socio-economical scales: among the attractions that the sidewalks may pose are the seasonal fairs and offering artistic works, street theaters and so forth to give social spree and alacrity and dynamicity and spatial attractiveness to the walkways (Mortazavi, 2011). Also, constructing the sidewalks mostly takes place along the culturally and historically attractive spots and this can corroborate the social and cultural life. One of the other important walking and jogging culture prevalence indices are the safety and security rate on the streets (Mo'eeni, 2006) and the urban space round the clock activities (Kashanijoo, 2011).

2. Spatial-textural scales: organizing the sidewalks is one of the effective factors in booming the traditional and new retailer centers and easy and ready accessibility to the small but necessary daily services (Mehdizadeh, 2000). The existence of blended and agglomerate business and residential uses is the main condition for 24-hour activities on the sidewalks as part of the urban space and especially the focus is on the placement of the retailer shops on the first floors and residential uses laid upon the higher floors (kashanijoo, 2011). It is necessary for the business shops, vagabonds, restaurants, coffee shops to exist to create attraction and elevate the vivacity and diversity (Mortazavi, 2011).

3. Traffic and accessibility scales: pedestrians' trips should be planned in connection to the passenger trips. Without pedestrian being present other types of traffics and movements are meaningless. Therefore, the pedestrian traffic should provide for the necessity with which the other forms of movements and transportations are planned and it should come first in intracity transportation planning. Furthermore, the sidewalk paths and venues should connect the whole urban activities in the form of a continuous and incessant network in such a manner that the pedestrian accessibility can be provided for easily and readily (Gharib, 2004).

Appointing places for taxi stations and spots for the automobiles to discharge and load passengers in the vicinity of the pedestrians' passage ways is also envisaged as being necessary. Also, the sidewalk plots should not be a drive for accumulating traffic in the other sections of the business centers (Pakzad, 2005).

4. Urban designing scales: creating appropriate flooring, paying attention to the sky line, designing the bodies and the peripheral environments can enhance the path quality. To avoid monotonous views it is necessary for the stoppage points to be created. Creating localities for 
sitting, installing appropriate lighting posts, public toilets are among the elements of a versatile designing of the path for the movement of the pedestrians and footers. Moreover, creation of vivid and clear-cut navigation systems free of causing interference can supplement the path design (Gharib, 2004). Paying attention to the climate effects on the sidewalks, bioenvironmental pollutions and the role of vegetative covers is also deemed as being necessary (Mehdizadeh, 2000).

\section{Vivacity:}

The American institution for the architects (AIA) prepared and published a compilation in 2005 entitled "vivacity", in which meanwhile stating that it is not possible to offer a definite and certain definition for vivacity and that the vivacity in a place should be specified and defined according to the characteristics of the inhabitants residing therein, presented a general concept to elaborate the discussions regarding vivacity and in this general concept vivacity was realized as having identity, dynamicity, flexibility and adaptability with the new needs. Vivacity is attributed to a system which contributes to the physical, psychological, social and personal progress in the residents and as for the urban spaces it is a favorable and optimum situation which creates and reflects spiritual and cultural enrichment (Timmer and Nola, 2005). In 1997, Henry Lenard also in his book which was named "urban revitalization" publishes principles defining a vivacious city in which vivacity and reinvigoration have been defined as the possibility for watching the people and hearing their voices, the probability for gathering around informally of the people in public areas, the chance to become socialized for the children and youngsters, confirmation and the citizens mutual respects directed toward one another and respecting the other residents cognition and awareness. "Vancouver work group discussions" in an article prepared in 2005 has defined a vivacious city as a complete urban system with social, cultural and bioenvironmental aspects and vivacity has also been defined as the quality of the life that can be experienced by the inhabitants and residents of a city or a region which has the dimensions of accessibility (to the infrastructures, food, clean air, cheap accommodation, recruitment, green areas and parks), equality (in access to the infrastructures and security and safety) and participation (in making decisions for satisfying their needs). So, vivacity has been defined as possessor of various interrelated social, economical, cultural and bioenvironmental components (Rafi'eeian, 2010). In the public spaces guidelines for the people which has been published in 2007 successful urban spaces vivacity has been specified in the localities' 
dynamicity, activity, safety and security, comfort, diversity and the ability of the place to amuse the others (Khastoo and Sa'eedi Rezvani, 2010). In Yangol's idea an animate and vivacious place is a place where the people select it for taking a rest, staying and meeting, rather than wishing to pass by it rapidly. What is overtly clear is that the vivacious space is more dependent on the number of the minutes spent by the individual outside the home rather than the number of the people who are outside. In other words, increasing the quality of the space and consequently inclination towards staying and spending time in there is almost simpler and more efficient than wishing to increase the number of the visitors. Furthermore, working on the time and quality rather than to work with the quantity will be enhancing the space to the best interests of everyone and on the entire days of the year. Common spaces in a vivacious and reinvigorated street are centers for the social life and it is the focal point for the entire society's attention. The vivacious space should be built or repaired in the form of an interconnected and continuous network; in such a manner that the sidewalks and the cycling venues sew and stitch the entire areas with collective quality and social life. Vivacity and dynamicity of the urban spaces and quite oppositely their dullness is reflective of the number and especially the type of the activities and incidents happening therein. Therefore, for the identification of vivacity firstly we need to survey the activities that can be happening in such spaces. "These activities can encompass the entire human activities which are taken in line with satisfying one of his or her needs". Yangol, the Danish city builder, divides such activities into three sets depending on their being optional or compulsory which include, the necessary (compulsory) activities such as going to school or work, waiting in bus stops, purchasing the arbitrary activities (recreational) such as park-going and generally having fun and social activities such as watching the others, having conversation, attracting the attention of the others. A space can be thought of as being vivacious and revived that in a vast and extensive span of the day different types of the individuals choose to go there and not that they have been taken there by force and spend some time therein; to put it differently, it means that the space should be in such a manner that the people prefer to come and stay (Gehl, 2010). In order to provide for the grounding for the people to be attracted to such spaces and then retaining them in the space firstly there is a need for the attractive and fascinating elements and factors to be present and also the people should see no problems in staying therein and spend their times satisfactorily. Therefore, two factors of attractiveness and satisfaction should be taken into consideration as the primary prerequisites for the vivacity of an 
urban space and every factor that somehow provides the people with attractiveness and satisfaction in urban space can be useful (Berambilla and Gionni, 1977).

\section{Study methodology:}

In the present study firstly we dealt with the survey of the specialized contexts regarding the feasibility and implementation ability scales of pedestrianization and its relation to the social vivacity, and the data were gathered through taking advantage of analytical-descriptive methods and based on documentary-library studies and in the next stage the information collected was studied via the application of field studies and questionnaires and interviewing with the users of Hakim Nazari Street. The compiled questionnaire (which was structurally designed in two parts including the pedestrian-oriented approaches and the citizens' vivacity according to the study analytical framework) was administered during 6 consecutive days (all week days) in different hours of the day (morning, noon, night) to 365 individuals both men and women and within the age range from 15 to 65 years of age all of whom were from different social classes (residents, businessmen and women, space users) based on a systematic random method on Hakim Nazari route and also the individuals were interviewed. After the questionnaires were completed, eventually we came up with 320 questionnaires which were qualified from the perspective of the information value and these were analyzed. In this investigation the feasibility and the convertibility of Hakim Nazari Street to a vivacious and reinvigorated auto-free precinct was surveyed.

The study population sample volume was estimated based on Cochran formula (formula 1) to be 365 individuals which includes:

Formula 1: Cochran formulae

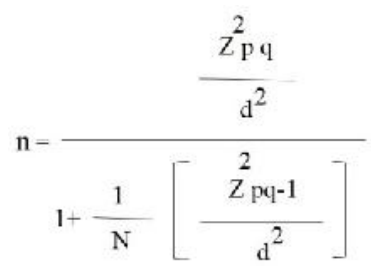

where, $\mathrm{N}$ is the number of the study population members, $\mathrm{n}$ is the number of the study sample volume and $\mathrm{p}$ and $\mathrm{q}$ are equal to 0.5 .

\section{Findings:}


Introducing the study area, Birjand County is the Southern Khorasan capital and it is located in the eastern breadth of Iran. The city verges to Qa'enat County from the north, to Darmyan and Sarbisheh Counties from the east and to Nehbandan and Kerman Province from the south, to the Sarayan and Tabas cities from the west and the city population reaches to a number of 260 thousand people based on the census conducted in 2011 and the study area reaches to 34893 square meter.

Hakim Nazari Street is situated in the central part of the city of Birjand; it is within the jurisdiction of the district 2 of the region 1 according to the municipality classifications. This street is a unidirectional route on which the traffic moves from Shohada' Square towards Imam Square and it plays a role in the city accessibility and convenience hierarchy. This route is adjacent to Montazeri Street from the east side, from the west brink it is adjacent to $17^{\text {th }}$ Shahrivar street (also known as art university street and Zahedan street), in its northern border the street is next to Imam Khomeini (his tomb is sacred) Square and Jomhoori Eslami Street, from the southern section it is in the vicinity of the Shohada' Square and the Shohada' Street. And the route is of a great importance due to being close to some of the significant elements in the city such as Ha'eri Mosque, the Great Bazaar entrance which are impregnated with various sorts of business activities on its entire path and also because of being situated in the distance between the two important juncture points (Imam Khomeini (his tomb is sacred) Square and Shohada' Square) which can be served as focal points for attracting the individuals and a place for the various social, economical and cultural incidents to take place and all of these aforementioned factors have caused us to nominate the street as a route with the potential to be transformed into a pedestrianized sidewalk.

Figure (1) has illustrated Hakim Nazari Street area in the city of Birjand.

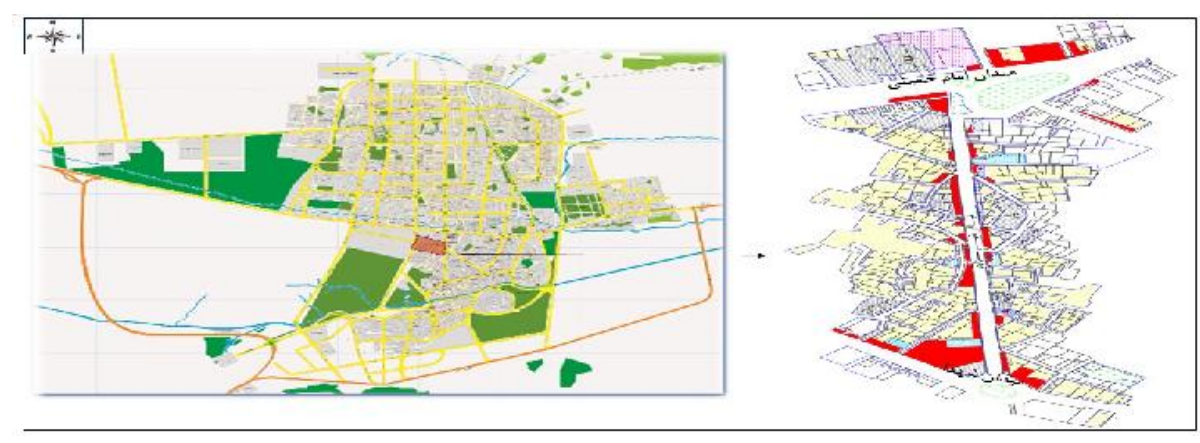

Fig.1. Introducing Hakim Nazari Street area in the city of Birjand 
In this section, table (1) pertaining to the SWOT technique has been prepared for the study area to present a full-scale introduction and recognition of the entire aspects influencing the study subject matter.

Table 1. SWOT analytical technique

\begin{tabular}{|c|c|c|}
\hline Index & Strength (S) & Weakness (W) \\
\hline \multirow[t]{5}{*}{ Texture } & $\begin{array}{l}\text { The existence of the } \\
\text { coordinated and } \\
\text { orderly sky line and } \\
\text { ground line along } \\
\text { the path }\end{array}$ & $\begin{array}{l}\text { - The site is in the } \\
\text { city's } \\
\text { texture area }\end{array}$ \\
\hline & $\begin{array}{l}\text { - The existence of } \\
\text { congruence in the } \\
\text { type of the masonry } \\
\text { used for the } \\
\text { buildings }\end{array}$ & $\begin{array}{l}\text { - High permeability } \\
\text { due to the numerous } \\
\text { and } \\
\text { accessibilities to the } \\
\text { area }\end{array}$ \\
\hline & $\begin{array}{l}\text { - The relatively } \\
\text { optimum level of the } \\
\text { site lighting system }\end{array}$ & $\begin{array}{l}\text { - The area is in a } \\
\text { disorderly } \\
\text { organic texture }\end{array}$ \\
\hline & $\begin{array}{l}\text { - The existence of } \\
\text { vegetative cover in } \\
\text { the area (even not so } \\
\text { much dense) }\end{array}$ & $\begin{array}{l}\text { - The existence of } \\
\text { unstable and old } \\
\text { buildings in the area } \\
\text { devoid of the } \\
\text { architectural value }\end{array}$ \\
\hline & $\begin{array}{l}\text { - Hakim Nazari route } \\
\text { is between two } \\
\text { squares with a high } \\
\text { volume of traffic } \\
\text { (Imam Khomeini (his } \\
\text { tomb is sacred) } \\
\text { Square and Shohada' } \\
\text { Square) }\end{array}$ & $\begin{array}{l}\text { - The high slope of the } \\
\text { tributary passage } \\
\text { ways stemming out } \\
\text { from Hakim Nazari } \\
\text { route }\end{array}$ \\
\hline Performance & $\begin{array}{l}\text { The existence of } \\
\text { some stoppage points } \\
\text { and nesting areas in } \\
\text { some parts of the } \\
\text { route including in } \\
\text { front of the mosque, } \\
\text { great bazaar entrance } \\
\text { gate, in front of }\end{array}$ & $\begin{array}{l}\text { - The site is in the } \\
\text { worn-out texture of } \\
\text { the city }\end{array}$ \\
\hline
\end{tabular}




\begin{tabular}{|c|c|c|c|}
\hline & & mobile passage & \\
\hline & & $\begin{array}{l}\text { The existence of } \\
\text { some service use } \\
\text { cases including } \\
\text { banks, and the } \\
\text { financial and credit } \\
\text { institutes and } \\
\text { business shops in the } \\
\text { body of the site }\end{array}$ & $\begin{array}{l}\text { - Over } 90 \% \text { of the } \\
\text { existing buildings are } \\
\text { privately owned from } \\
\text { the perspective of the } \\
\text { buildings possession } \\
\text { status }\end{array}$ \\
\hline & & $\begin{array}{l}\text { The existence of the } \\
\text { Imam Square police } \\
\text { station No. } 12 \text { in the } \\
\text { vicinity of the site } \\
\text { which potentially } \\
\text { brings about more } \\
\text { safety and security }\end{array}$ & $\begin{array}{l}\text { The existence of the } \\
\text { parked cars along the } \\
\text { route due to the lack } \\
\text { of parking lots }\end{array}$ \\
\hline & & $\begin{array}{l}\text { The existence of the } \\
\text { Imam Square police } \\
\text { station No. } 12 \text { in the } \\
\text { vicinity of the site } \\
\text { which potentially } \\
\text { brings about more } \\
\text { safety and security }\end{array}$ & $\begin{array}{l}\text { - The existence of the } \\
\text { parked cars along the } \\
\text { route due to the lack } \\
\text { of parking lots } \\
\text { - The lack of easy } \\
\text { access to the public } \\
\text { transportation means } \\
\text { including taxi and } \\
\text { bus }\end{array}$ \\
\hline Interpretation & & $\begin{array}{l}\text { The absence of } \\
\text { explicit cultural and } \\
\text { social disputes } \\
\text { resulting in troubles } \\
\text { among the citizens }\end{array}$ & $\begin{array}{l}\text { - The lack of budget } \\
\text { and civil projects } \\
\text { credits }\end{array}$ \\
\hline & & $\begin{array}{l}\text { The existence of } \\
\text { business entities in } \\
\text { the study area }\end{array}$ & $\begin{array}{l}\text { The existence of } \\
\text { some old and } \\
\text { inefficient } \\
\text { regulations }\end{array}$ \\
\hline & & $\begin{array}{l}\text { Coordination } \\
\text { between the extant } \\
\text { elements in the } \\
\text { texture with } \\
\text { historical and old } \\
\text { backgrounds }\end{array}$ & $\begin{array}{l}\text { - Lack of attentiveness } \\
\text { and low agility in } \\
\text { some of the organs in } \\
\text { the urban area } \\
\text { (maybe due to the } \\
\text { lack of expertise and }\end{array}$ \\
\hline
\end{tabular}




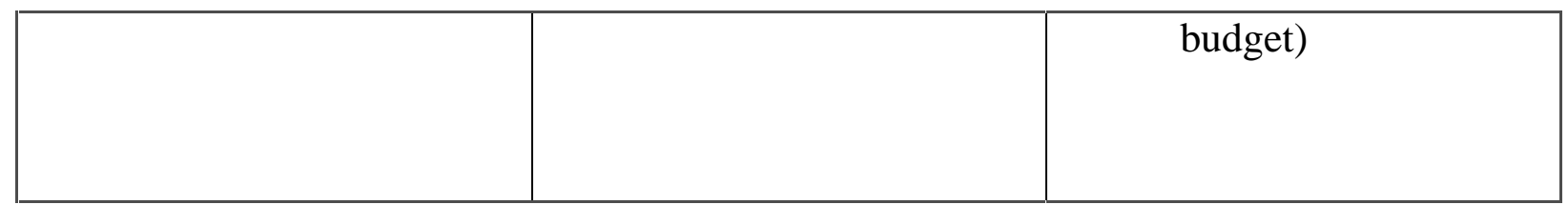

Continuation to table (1)

\section{Index}

Opportunity (O)

Threats (T)

Texture

- The possibility for binding the valuable historical points in the periphery of the site through creating this auto-free precinct
- The possibility for indexing the site's performance signs according to the principle of harmony with the background; for example visual emphasis on the functional elements such as Ha'eri Mosque

- The possibility for creating a definite entrance to the Great Bazaar originating from this route

- The possibility to make use of a free of confusion and interference and extensive view along the route for the
The lack of the possibility of the route accountability regarding the passing traffic according to its small width in confrontation with the high volume of traffic and the unidirectionality of the route and the presence of the cars parked along the route as well 


\begin{tabular}{|c|c|c|}
\hline & $\begin{array}{l}\text { purpose of creating a } \\
\text { view corridor or } \\
\text { axial view } \\
\text { The possibility for } \\
\text { distributing Hakim } \\
\text { Nazari traffic to the } \\
\text { peripheral streets or } \\
\text { transforming an } \\
\text { appropriate tributary } \\
\text { route to shortcut }\end{array}$ & \\
\hline Performance & $\begin{array}{l}\text { - The possibility for } \\
\text { making use of site's } \\
\text { peripheral potentials } \\
\text { for the purpose of } \\
\text { enhancing the } \\
\text { pedestrians' } \\
\text { attraction } \\
\text { performance such as } \\
\text { Cinema Bahman } \\
\text { The possibility for } \\
\text { economical booming } \\
\text { through pulling } \\
\text { people to the urban } \\
\text { areas } \\
\text { The possibility for } \\
\text { enhancing the quality } \\
\text { of the urban spaces } \\
\text { through enhancing } \\
\text { the spaces vivacity, } \\
\text { enhancing the } \\
\text { security and spaces } \\
\text { efficiency; as a result } \\
\text { of pedestrianisation } \\
\text { - }\end{array}$ & $\begin{array}{l}\text { - The possibility of } \\
\text { creating } \\
\text { inconsistencies } \\
\text { between the area's } \\
\text { uses during the } \\
\text { course of time; since } \\
\text { at present they are } \\
\text { placed next to one } \\
\text { another } \\
\text { purposelessly and not } \\
\text { according to a proper } \\
\text { plan which need to } \\
\text { be organized }\end{array}$ \\
\hline Interpretation & $\begin{array}{l}\text { - Paying attention to } \\
\text { Hakim Nazari route } \\
\text { pedestrianization } \\
\text { with an approach to } \\
\text { the issue as the } \\
\text { citizens' needs to be } \\
\text { satisfied }\end{array}$ & $\begin{array}{l}\text { - The possibility of a } \\
\text { social discontinuity } \\
\text { between the citizens } \\
\text { as a result of the lack } \\
\text { of creating sufficient } \\
\text { motivation for the } \\
\text { purpose of creating } \\
\text { gatherings an }\end{array}$ \\
\hline
\end{tabular}




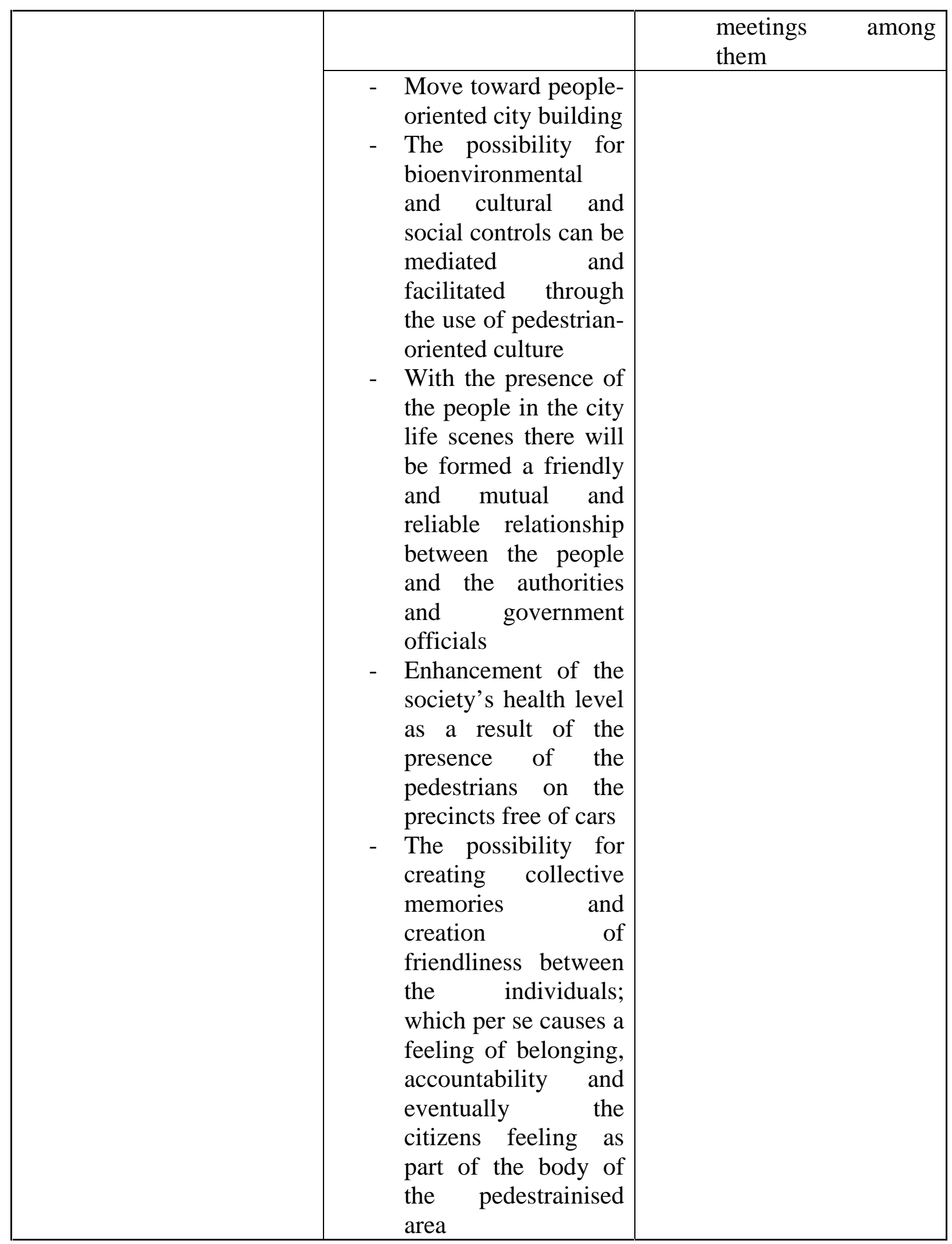




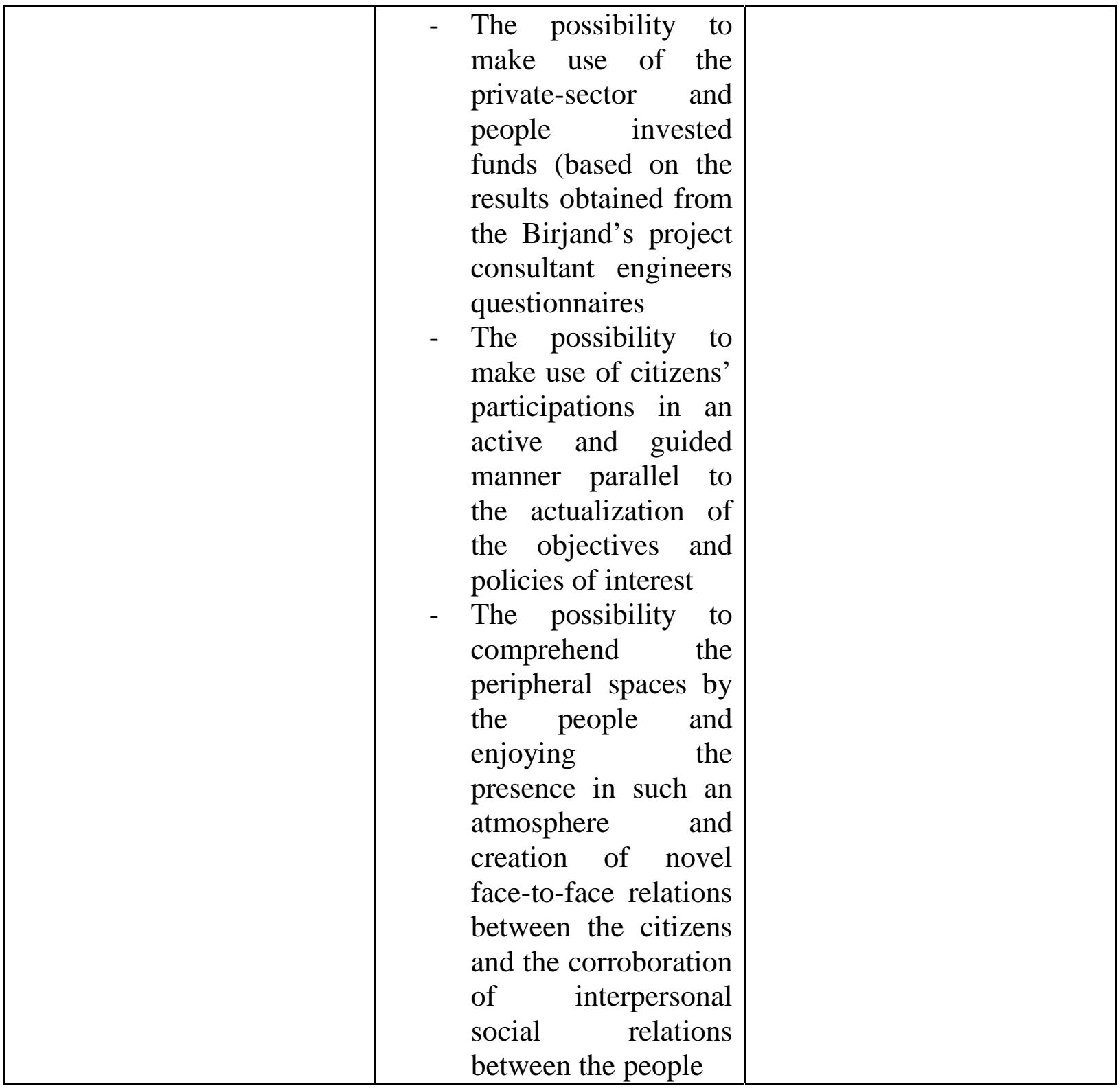

Source: the author

The information obtained from table (1) can be applied as a guideline in achieving the strategies and the policies required in confrontation with the study subject matter.

Analytical findings:

The dependent variable status (Hakim Nazari Street) and independent variables (the pedestrianisation indices with citizens' vivacity) based on one-sample t-test:

Based on the t-test the mean status of Hakim Nazari Street according to the environment users' ideas and notions (the study population) was found as being equal to 2.23 which (based on the 
table below) was shown to be in a good status and in coordination and accordance to the entire independent variables except the variables related to the pedestrian planning processes in connection to the other methods of public transportation (such as bus and taxi) and supplementary ones (such as bicycle) and the existence of appropriate parking lots, walking facilities (such as proper flooring, elimination of the surface discrepancies on the route, proper designing for the handicaps, place for resting and sitting, lighting systems, WCs, garbage bins, the method of carrying off the scene the surface waters), protection against the weather (due to the existence of items such as marginal green spaces, shades and marginal guards and shields), the scenes' visual fascination and the bodily attractiveness (such as the diversity and the rhythm in the body). Table (2) is indicative of the dependent variable (Hakim Nazari Street) and the independent variables (pedestrianization index with citizens' vivacity) statuses from the perspective of the users.

Table 2. the dependent and independent variables statuses (pedestrianization index with citizens' vivacity) from the perspective of the users

\begin{tabular}{|c|c|c|}
\hline Aspects & $\begin{array}{l}\text { Independent variables (pedestrianisation index with } \\
\text { social vivacity) }\end{array}$ & $\begin{array}{l}\text { Score: } \\
1<\text { mean }<3\end{array}$ \\
\hline \multirow[t]{3}{*}{$\begin{array}{l}\text { Textural } \\
\text { and spatial }\end{array}$} & $\begin{array}{l}\text { The existence of the retailer shops and leisure time use } \\
\text { cases and vagabonds and the presence of stoppage and } \\
\text { pause points }\end{array}$ & 2.01 \\
\hline & $\begin{array}{l}\text { Uses agglomerations and the existence of attractive } \\
\text { activities and the lack of inhibitory activities }\end{array}$ & 2.01 \\
\hline & $\begin{array}{l}\text { The existence of outstanding historical elements inside } \\
\text { the area or in its vicinity }\end{array}$ & 2.89 \\
\hline \multirow[t]{3}{*}{$\begin{array}{l}\text { Accessibility } \\
\text { scale and } \\
\text { traffic }\end{array}$} & $\begin{array}{l}\text { Pedestrianisation planning in connection to the other } \\
\text { methods of public transportation such as buses and taxis } \\
\text { and supplementary transportation means like bicycles } \\
\text { and appropriate parking lots }\end{array}$ & 1.91 \\
\hline & The sidewalks continuity and readability & 2.43 \\
\hline & $\begin{array}{l}\text { Absence of traffic disorders on the other regional } \\
\text { sections due to the pedestrianisation }\end{array}$ & 2.30 \\
\hline \multirow{2}{*}{$\begin{array}{l}\text { Social and } \\
\text { economical } \\
\text { scales }\end{array}$} & Involving a lot of pedestrians & 2.54 \\
\hline & $\begin{array}{l}\text { The participation between the businessmen and the } \\
\text { residents (for instance cooperation in implementation of } \\
\text { the plan or at least lack of resistance by the residents and }\end{array}$ & 2.37 \\
\hline
\end{tabular}




\begin{tabular}{|l|l|l|}
\hline \multirow{2}{*}{$\begin{array}{l}\text { Planning } \\
\text { subscales }\end{array}$} & $\begin{array}{l}\text { the businessmen and women) } \\
\text { Security and safety } \\
\text { flooring, the lack of surface discrepancies on the route, } \\
\text { proper planning for the handicaps, places for sitting and } \\
\text { resting, lighting system, WCs, garbage bins, the method } \\
\text { of carrying off the surface waters) }\end{array}$ & 2.49 \\
\hline & $\begin{array}{l}\text { Puman factor } \\
\text { Protection against the weather (as a result of existing } \\
\text { items such as marginal green spaces, shades and } \\
\text { marginal shields }\end{array}$ & 1.33 \\
\cline { 2 - 3 } & $\begin{array}{l}\text { The scenes' visual fascination and bodily attractiveness } \\
\text { (such as diversity and rhythm in the physical body of the } \\
\text { site) }\end{array}$ & 1.99 \\
\hline
\end{tabular}

Source: the author

\section{DISCUSSIONS AND CONCLUSION:}

As it was mentioned at the beginning of the article, the main objective of the current research is to evaluate the feasibility of transforming Hakim Nazari Street to a pedestrianised precinct with social vivacity. And the study question also posited that whether Hakim Nazari Street has the potential to be transformed into a car-free pedestrian precinct with the citizens' vivacity? And it was indicated in the current research that according to the pedestrianisation index and with the attainment of a score equal to 2.23 from the total score of 3 Hakim Nazari Street has the potential and capability to be turned into a auto-free pedestrian precinct. The study hypothesis was also laid upon the premise that "Hakim Nazari Street has the capability to be changed into a pedestrianised route with citizens' vivacity according to its elements and potentials. And it was also shown that the proposed hypothesis has been confirmed to wit Hakim Nazari Street in the city of Birjand can be a place for various social, economical and cultural events to take place due to being in the possession of potentials such as Ha'eri Mosque, the Great Bazaar entrance gate, various sorts of business activities in its walls and also due to being emplaced between two important junctures (Imam Khomeini (his tomb is sacred) Square and Shohada' Square). In other words, due to the aforementioned potentials and competencies the study area can be turned into a pedestrian-only route for attracting the people and then vivacity and booming and urban joyfulness would be the outcomes which one can expect from the implementation of such a project plan. It can be said that the present study findings are consistent with the other studies' 
findings, in such a way that in the presents study it has been tried to come up with a fruitful and executive generalization regarding the study subject matter and then we can proceed to the customization of the study targets.

Also, the results obtained from the studies performed indicate that regarding the analysis of the responses given for the questions within the format of the questionnaires in order to change Hakim Nazari Street to a pedestrian-only auto-free precinct full of vivacity the following general suggestions can be posed:

1. The appropriate distribution of Hakim Nazari Street passing traffic and parking lots within the adjacent passage ways in such a manner that it stays away from traffic congestion.

2. Attracting support and participation from the people's side in various processes (including plan procurement, plan implementation and exploitation of the plan), as the most original members with a high share of interest in the project; through clarification of the process, the results thereof and the project feedbacks and making the citizens conscious and aware.

3. Enhancing the cultural level in using the more stable states of transportation (such as walking and cycling) and elevation of the citizens' ecological awareness

4. Organization and placement of the various kinds of the uses and activities in the study area in a manner for it to be attractive to the people and encouraging to the citizens' pedestrian-orientation attitudes.

5. Placement of the urban furniture along the pedestrian route in such a manner that it can be accountable and satisfying the citizens' needs both qualitatively and quantitatively. Moreover, in such a manner that it can bring about dynamicity and visual enjoyment and corroborating of the space sensual enrichment and also it can provide the citizens with comfort and ease. Also, it is worth mentioning that designing of the furniture should be conducted proportionate to the users' identity and spatial background and culture and needs.

\section{REFERENCES:}

- Izadi, Muhammad Sa'eed, 2010, "the elements and the constituents of the Islamic Iranian cities with an emphasis on the public spaces and their functions", the first conference for the elaboration of the Islamic Iranian city-building patterns and architecture, Hamadan 
- Madanipoor, Ali, 2008, "designing the urban spaces", the urban processing and planning company

- Rafi'eeyan, Mojtaba, 2010, “citizens and public urban spaces”, Islamic Azad University, Tehran

- Angoorani, Mika'eel, "beauty, happiness, vivacity, city-building goals”, 2010, 22: 29-34

- Ghaffari, Ali, Soheylipoor, Sadegh, 2010, “public spaces and collective life book's translation", by Yangol, 65

- Fallah, Manshadi, Elham, Habibi, Sara, Rouhi, Amir, "the evaluation of the Tehran's bazaar pedestrian precinct", the center for the city of the Tehran's studies and plannings, $2012,125(11)$

- Mortazavi, Sabooha, "recognition of the pedestrian routes as a grounding for spending one's leisure time in the cities", Outlook monthly Journal, 2011, 12, 17

- Gharib, Fereydoon, "the evaluation of the feasibility study for creating pedestrian and cycling routes in the periphery of Old Tehran", aesthetic arts, 2004, 19(34)

- Abbaszadegan, Mustafa, "modern architecture theory-urbanization movement towards urban spaces", the monthly journal of municipalities, Tehran, 2004, 67(58)

- Muhammadzadeh, Rahmat, "the existing perspectives in the development of the pedestrian walk ways network", the journal of geographical researches, $10^{\text {th }}$ year, 1995, $37,121-138$

- Pakzad, Jahanshah, "the urnban spaces designing guidelines in Iran", Payam Sima designing and publication company, the ministry of accommodation and city-building, 74

- Habibi, Seyyed Muhsen, 2001, "the pedestrian route for recreation”, the journal of aesthetic arts, 2005, 9, 43-51

- Ghorbani, Rasool, Jam Kasra, Muhammad, "pedestrianisation expansion movement, a modern approach to reviving the urban centers", urban and regional studies and researches, 2010, 6: 55-72

- Shaghaghi, Pejman, 2007, "Sattarkhan Street pedestrianisation", BA dissertation paper, Shahid Beheshti University

- Mohammadian Mosammam, Hassan, 2012, "the feasibility evaluation of Hamadan city center streets pedestrianisation", BA dissertation paper, Shahid Beheshti University

- Mo'eeni, Seyyed Mahdi, “pedestrian-oriented cities”, Azarakhsh, $2^{\text {nd }}$ ed., Tehran, 
pp.100-103, 2012.

- Ashouri, Ali, "the survey of the role of pedestrianisation in the city life", the specialized monthly journal of outlook, 2010, 8 .

- Kashanijoo, Khashayar, 2011, "sidewalks (from the designing basics to the functional features)", Azarakhsh, Tehran

- Kashanijoo, Khashayar, "the importance of the pedestrian spaces in the third millennium cities, city-building objectives", 2006, 18: 40-52

- Thaghafi Asl, Arash, "the importance and the role of the sidewalks in the sustainable transportation network, city-building objectives, 2008, 26: 27

- Mo'eeni, Seyyed Muhammad Mahdi, “the enhancement of the pedestrian-orientation capability, a step towards more humane cities”, aesthetic arts, 2006, 27: 5-16

- Mehdizadeh, Javad, "walking and footing concepts and principles", the monthly journal of the municipalities, 2000, 159: 12

- Khastoo, Maryam, Sa'eedi Rezvani, Navid, "factors contributing to the urban spaces vivacity, creating a vivacious urban space with an emphasis on pedestrian purchase center concept", the journal of Howiat, no.6, Islamic Azad University, Qazvin Branch, pp.63-74, 2010.

- Frain, John., (2004).Planning and Design for Pedestrians.Time-saver standards for UrbanDesign,16

- Berambilla, Robertoand Gionni, Longo,(1977). For pedestrians Only (planning, design and management of traffic - freezones), Whitrry library of design, 60

- Hass, klau., (1990). The pedestrian and city traffic.London, Belhaven Press, pp 17

- Southworth, Micheal.; Designing the walkable city journal of urbanplanning development, 2005: 246-257

- Timmer, Vanessa and Nola, Kate, Seymoar,(2005); The world Urban from 2006, Vancouver the livable, 43

- Gehl, Jan .,(2010); Cities for people, Island press, vashington, USA,72

May god bestow you with success

\section{How to cite this article:}

Alimardani M, Aftabi M, Dehghani A. The survey of pedestrainization feasibility in urban spaces and its relationship with the citizens' vivacity. Case study: the city of birjand's hakim nazari street. J. Fundam. Appl. Sci., 2016, 8(2S), 1650-1676. 